\title{
Hybrid imaging with PET/CT and PET/MR
}

\author{
Andreas Kjaer \\ From International Cancer Imaging Society (ICIS) 14th Annual Teaching Course \\ Heidelberg, Germany. 9-11 October 2014
}

Hybrid PET/MRI systems have recently become commercially available with potential to change medical imaging by providing combined anatomical-metabolic image information. Especially in cancer patients, this may be of benefit.

PET itself is widely used in everyday routine due to its capability of providing molecular information used mainly for the non-invasive characterization of tumors and metastases [1,2], as well as for monitoring effect of cancer therapy [3]. However, PET images contain no detailed anatomical information and, therefore benefits from fusion with morphological image information from CT. Accordingly, since PET/CT systems became available oncological PET examinations have mainly been performed as combined PET/CT which has been proven of higher diagnostic value than separate PET or CT imaging in a number of clinical indications [4]. Recently, hybrid PET/MRI scanners were introduced and made available. However, PET/MRI is more costly and with a lower throughput than PET/CT. Accordingly, the question arises when and if PET/MRI should be used in cancer patients. MRI has the advantages compared to CT, that it may also be considered a functional imaging technique in addition to its anatomical capabilities. This may be of particular relevance in cancer patients in view of need for planning tailored therapy and for monitoring response to treatment $[5,6]$. Compared to CT, also the anatomical capabilities of MRI are often superior due to better softtissue contrast.

The knowledge obtained from molecular imagingguided therapies e.g. using FDG-PET for predicting therapy response in lymphomas [7], could quickly be transferred to PET/MRI, for a combined multi-parametric strategy. Accordingly, hybrid PET/MRI scanners might become game-changers for how MRI is used in clinical routine.

Correspondence: akjaer@sund.ku.dk

Dept. of Clinical Physiology, Nuclear Medicine \& PET, Rigshospitalet,

University of Copenhagen, 2000 Copenhagen, Denmark
At the Department of Clinical Physiology, Nuclear Medicine \& PET at Rigshospitalet in Copenhagen we have currently PET/MRI scanned more than 1,200 patients and our experience so far will be presented and discussed with focus on whether PET/MRI fulfills a real clinical need within oncology or should (still) be considered an expensive research tool and the challenges of PET/ MRI $[8,9]$.

\section{Published: 9 October 2014}

\section{References}

1. Kjaer A: Molecular imaging of cancer using PET and SPECT. Adv Exp Med Biol 2006, 587:277-284.

2. Gambhir SS: Molecular imaging of cancer with positron emission tomography. Nature Rev Cancer 2002, 2(9):683-693.

3. Wahl RL, Jacene H, Kasamon Y, Lodge MA: From RECIST to PERCIST: Evolving Considerations for PET response criteria in solid tumors. J NuCl Med 2009, 50(Suppl 1):122S-150S.

4. Delbeke D, Schoder H, Martin WH, Wahl RL: Hybrid imaging (SPECT/CT and PET/CT): improving therapeutic decisions. Sem NuCl Med 2009, 39(5):308-340.

5. Padhani AR, Koh DM, Collins DJ: Whole-body diffusion-weighted MR imaging in cancer: current status and research directions. Radiology 2011, 261(3):700-718.

6. Padhani AR, Liu G, Koh DM, Chenevert TL, Thoeny HC, Takahara T, DzikJurasz A, Ross BD, Van Cauteren M, Collins D, Hammoud DA, Rustin GJ, Taouli B, Choyke PL: Diffusion-weighted magnetic resonance imaging as a cancer biomarker: consensus and recommendations. Neoplasia 2009, 11(2):102-125.

7. Hutchings M, Loft A, Hansen M, Pedersen LM, Buhl T, Jurlander J, Buus S, Keiding S, D'Amore F, Boesen AM, Berthelsen AK, Specht L: FDG-PET after two cycles of chemotherapy predicts treatment failure and progressionfree survival in Hodgkin lymphoma. Blood 2006, 107(1):52-59.

8. Kjær A, Loft A, Law I, Berthelsen AK, Borgwardt L, Löfgren J, Johnbeck CB, Hansen AE, Keller S, Holm S, Højgaard L: PET/MRI in cancer patients: first experiences and vision from Copenhagen. MAGMA 2013, 26(1):37-47, doi: 10.1007/s10334-012-0357-0. Epub 2012 Dec 25. PubMed PMID: 23266511.

9. Keller SH, Holm S, Hansen AE, Sattler B, Andersen F, Klausen TL, Højgaard L, Kjær A, Beyer T: Image artifacts from MR-based attenuation correction in clinical, whole-body PET/MRI. MAGMA 2013, 26(1):173-81, doi: 10.1007/ s10334-012-0345-4. Epub 2012 Sep 21. PubMed PMID: 22996323.

doi:10.1186/1470-7330-14-S1-032

Cite this article as: Kjaer: Hybrid imaging with PET/CT and PET/MR. Cancer Imaging 2014 14(Suppl 1):O32.
C Biomed Central

(C) 2014 Kjaer; licensee BioMed Central Ltd. This is an Open Access article distributed under the terms of the Creative Commons Attribution License (http://creativecommons.org/licenses/by/4.0), which permits unrestricted use, distribution, and reproduction in any medium, provided the original work is properly cited. The Creative Commons Public Domain Dedication waiver (http://creativecommons.org/publicdomain/zero/1.0/) applies to the data made available in this article, unless otherwise stated. 